\title{
Rancangan Pusat Industri Kreatif dengan Tema Neo-Vernakular di Kabupaten Kutai Kartanegara
}

\author{
Salsadilla Rizky Nur Khalalya ${ }^{1}$, Esty Poedjioetami ${ }^{2}$, Randy Pratama Salisnanda ${ }^{3}$ \\ 1,2,3 Jurusan Arsitektur, Fakultas Teknik Sipil dan Perencanaan, Institut Teknologi Adhi Tama Surabaya, \\ Surabaya, Indonesia \\ Email: salsadillarizky03@gmail.com ${ }^{1}, \underline{\text { ren.salisnanda87@gmail.com }{ }^{3}}$
}

\begin{abstract}
The people of Kutai Kartanegara Regency themselves have characteristics and creativity that have great potential for the development of their cultural arts which is quite thick, especially in the field of performing arts. Kutai Kartanegara Regency has 18 subdistricts that have various kinds of performing arts as their creative potential. The Center for Creative Industries in Kutai Kartanegara Regency will become a centralized and integrated forum for art movers in Kutai Kartanegara Regency. Keatif Industry Center in Kutai Kartanegara Regency with a Neo Vernacular architectural approach that creates designs with the aim of restoring elements of local culture typical of East Kalimantan by undergoing renewal to become a more modern work without reducing the rules of traditional values. The micro concept of Centralized land arrangement, making the land arrangement leads to one side or the main center of creative industry activities. The concept of micro form (Attractive Culture), creating a building form with an attractive concept is appointed because it is able to represent the essence of the object as a cultural tourism building. The concept of micro space (Adaptive Culture), creates a design space that functions and can accommodate all creative industry activities, designing a space starting from embracing the elements and atmosphere of its culture, then adjusting to the function of each designed space.
\end{abstract}

Keywords: Industry Creative, Kabupaten Kutai Kartanegara, Neo Vernakular

\begin{abstract}
Abstrak. Masyarakat Kabupaten Kutai Kartanegara sendiri memiliki ciri khas dan kreatifitas yang berpotensi besar untuk perkembangan seni budayanya yang cukup kental terutama di bidang seni pertunjukkan. Kabupaten Kutai Kartanegara memiliki 18 kecamatan yang memiliki berbagai macam kesenian pertunjukan sebagai potensi kreatifnya. Pusat Industri Kreatif Di Kabupaten Kutai Kartanegara akan menjadi sebuah wadah terpusat dan terintegrasi bagi para penggerak seni di Kabupaten Kutai Kartanegara. Pusat Industri Keatif Di Kabupaten Kutai Kartanegara dengan pendekatan arsitektur Neo Vernakular yang menciptakan desain dengan tujuan mengembalikan unsurunsur budaya lokal khas Kalimantan Timur dengan mengalami pembaruan untuk menuju suatu karya yang lebih modern dengan tidak mengurangi kaidah-kaidah nilai tradisi. Konsep mikro tatanan lahan Terpusat, menjadikan tatanan lahan mengarah pada satu sisi atau pusat utama kegiatan industry kreatif. Konsep mikro bentuk (Attractive Culture), menciptakan bentuk bangunan dengan konse atraktif diangkat karena mampu mewakili esensi objek sebagai bangunan wisata kebudayaan. Konsep mikro ruang (Adaptive Culture), menciptakan desain ruang yang berfungsi dan dapat menampung segala kegiatan industri kreatif, mendesain ruang dimulai dari mengangkan unsur dan suasana kebudayaannya, lalu menyesuaikan dengan fungsi tiap ruang yang di desain.
\end{abstract}

Kata Kunci: Industri Kreatif, Kabupaten Kutai Kartanegara, Neo Vernakular

\section{Pendahuluan}

Untuk meningkatkan potensi ekonomi di Kabupaten Kutai Kartanegara diperlukan adanya sebuah tempat atau bangunan yang dapat mewadahi kegiatan industri kreatif. Sampai saat ini belum ada gambaran yang jelas mengenai kondisi industri kreatif di Kabupaten Kutai Kartanegara. Padahal untuk Kabupaten Kutai Kartanegara sendiri sudah sangat banyak Sumber Daya Manusia yang mulai mengembangkan usaha industri kreatif secara mandiri di beberapa kawasan di Kabupaten Kutai Kartanegara, hanya saja masih sangat minim akan fasilitas dan pengembangannya. Banyaknya kegiatan di Kota Tenggarong Kutai Kartanegara, seperti Erau, Erau Adat Kutai International Folk Arts Festival 
$(E I F A F)$, Festival Kota Raja, dan kegiatan lainnya, telah menjadi pemicu untuk pertumbuhan ekonomi masyarakat ("EIFAF Event Budaya Berlevel Internasional," 2016; "Semarakkan HUT Tenggarong Ke236, Festival Kota Raja Dan Tenggarong Fair Kembali Digelar," 2018). Adaya kegiatan pemicu pertumbuhan ekonomi tersebut di Kota Tenggarong Kutai Kartanegara tak lain memunculkan kebutuhan akan sebuah ruang untuk mewadahi kegiatan publik.

Beragam kegiatan festival budaya di Tenggarong, merupakan salah satu jenis pengembangan warisan budaya yang juga sebagai daya tarik wisata (Astiti, 2015; Kurniawan, 2015). Dalam rangka mendukung potensi dan daya tarik wisata di Tenggarong, memerlukan adanya penciptaan industri kreatif yang berkaitan dengan pengembangan warisan budaya di Kota Tenggarong. Sehingga diperlukan adanya sebuah Pusat, yaitu sebuah tempat berkumpul bagi para pelaku industri kreatif di Kota Tenggarong. Selain sebagai tempat berkumpul para pelau industri kreatif, tempat itu juga dapat dijadikan sebagai tempat sinergisitas dari berbagai stakeholder baik Pemerintah, Akademisi, Penyedia modal, Asosiasi pengusaha, dan para pelaku industri kreatif yang dapat membantu mengambangkan industri kreatif di Kota Tenggarog Kutai Kartanegara. Perencanaan dan perancangan Pusat Industri Kreatif di Kabupaten Kutai Kartanegara nantinya akan mewadahi segala bentuk kegiatan ekonomi kreatif yang ada di Kabupaten Kutai Kartanegara. Bentuk ekonomi kreatif tersebut diantaranya yang berhubungan dengan kerajinan, desain, seni pertunjukan, film dan pertelevisian, musik, video dan fotografi, pasar barang antik hingga kuliner.

\subsection{Pemahaman mengenai Arsitektur Neo-Vernakular}

Arsitektur neo-vernakular, tidak hanya menerapkan elemen-elemen fisik yang diterapkan dalam bentuk modern tetapi juga elemen non fisik seperti budaya, pola pikir, kepercayaan, tata letak, religi dan lain-lain. "Neo" berasal dari Bahasa Yunani dan dugunakan sebagai fonim yang berarti baru. Neovernakular berarti Bahasa setempat yang diucapkan dengan cara baru. Arsitektur Neo-Vernakular adalah suatu penerapan elemen arsitektur yang telah ada, baik fisik (bentuk, konstruksi) maupun non fisik (konsep, filosofi, tata ruang) dengan tujuan melestarikan unsur-unsur lokal yang telah terbentuk secara empiris dan kemudian sedikit atau banyaknya mengalami pembaruan menuju suatu karya yang lebih modern atau maju tanpa mengesampingkan nilai-nilai tradisi setempat (Karmelia, 2017). Maka, Arsitektur Neo-Vernakular merupakan suatu paham dari aliran arsitektur Post-Modern yang lahir sebagai respon dan kritik atas modernism yang mengutamakan nilai rasionalisme dan fungsionalisme yang dipengaruhi perkembangan teknologi industri.

Arsitektur Neo-Vernakular merupakan arsitektur yang konsep dan kriterianya fisik dan nonfisiknya berdasarkan pada pertimbangan akan kaidah-kaidah normative (religi, kosmologis, peran serta budaya lokal dalam kehidupan masyarakat, serta keselaraan bangunan, alam, dan lingkungan). Penerapan kaidah-kaidah normatif ini tidak lain bertujuan untuk pelestarian unsur-unsur lokal (Purnamasari et al., 2019). Sebagai salah satu paham dari aliran post-modern, arsitektur neo-vernakular mengalami pembaruan menuju suatu karya yang lebih kekinian tanpa mengesampingkan pelestarian unsur lokal. Sehingga, desain arsitektur neo-vernakular yang khas dengan pertimbangan kaidah-kaidah normatif tepat untuk diterapkan pada suatu desain bangunan di lingkungan yang kuat akan unsur lokalitas budayanya.

Industri Kreatif dapat mengubah kreativitas dalam otak manusia menjadi kenyataan. Industri kreatif dapat meningkatkan pertumbuhan ekonomi, peningkatan struktur industri dan meningkatkan jumlah tenaga kerja. Menurut Wang dan Peng (dalam Sandroto et al., 2018), industri kreatif berbeda dengan industri barang yang diproduksi oleh mesin ataupun industri buruh dimana orang menjual tenaganya untuk mendapatkan upah, industri kreatif menghasilkan output modal intelektual yang berlabel originalitas. Industri Kreatif adalah: "Industri yang berasal dari pemanfaatan kreativitas, keterampilan, serta bakat individu untuk menciptakan kesejahteraan serta lapangan pekerjaan melalui penciptaan dan pemanfaatan daya kreasi dan daya cipta individu tersebut," (Pengembangan Ekonomi Kreatif Indonesia 2025 (Rencana Pengembangan Ekonomi Kreatif Indonesia 2009 - 2015), 2008). Industri kreatif yang memiliki 14 subsektor (periklanan; arsitektur; pasar seni dan barang antik; kerajinan; desain; fesyen; video, film dan fotografi; permainan interaktif; musik; seni pertunjukan; penerbitan dan percetakan; layanan komputer dan piranti lunak; televisi dan radio; dan riset dan 
pengembangan.) juga merupakan bentuk komitmen dalam bidang ekonomi kreatif itu sendiri (Putra et al., 2013). Dalam menggerakkan 14 subsektor tersebut, menuntut adanya ketersediaan wadah dalam beraktivitas dan berkreatifitas, yang memerlukan tema arsitektur neo-vernakular dalam perancangannya.

Lamin yang memiliki arti rumah panjang merupakan jenis arsitektur vernakular, banyak jumpai di wilayah Kalimantan Timur. Kondisi geografis Kalimantan Timur yang mempunyai banyak sungaisungai besar menjadi lokasi didirikan rumah Lamin oleh suku Dayak yang berdiam diri disepanjang sistem utama sungai tersebut. Rumah Lamin bagi masyarakat Dayak seperti sebuah desa yang seluruh anggota masyarakatnya hidup bersama dalam satu atap membentuk sebuah komunitas Rumah Lamin merupakan rumah adat yang ditinggali oleh masyarakat asal Kalimantan Timur dengan panjang sekitar 300 meter, lebar 15 meter, dan tinggi kurang lebih 3 meter. Rumah adat Lamin dianggap sebagai identitas masyarakat Dayak di Kalimantan Timur karena rumah ini mewakili kultur serta tradisi masyarakat sana yang turun temurun. Seperti rumah adat lainnya, Rumah Lamin juga adalah rumah dengan model panggung. Tempat tinggal ini memiliki model yang panjang dan sambung menyambung. Rumah dengan ukuran yang sangat besar ini membuatnya dapat menampung beberapa keluarga ("Rumah Adat Lamin di Kalimantan Timur," 2020; "Rumah Lamin," 2021; Welianto, 2021).

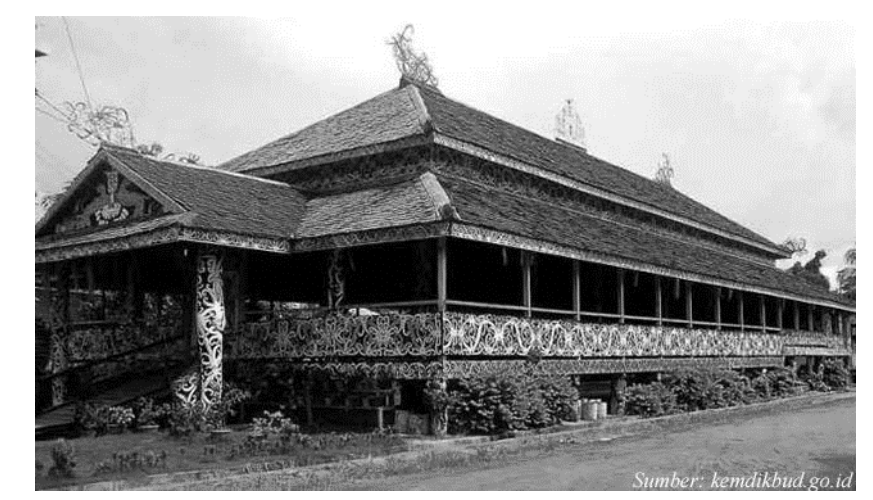

Gambar 1. Rumah Adat Lamin Kalimantan Timur Sumber : https://www.99.co/blog/indonesia/rumah-adat-lamin/

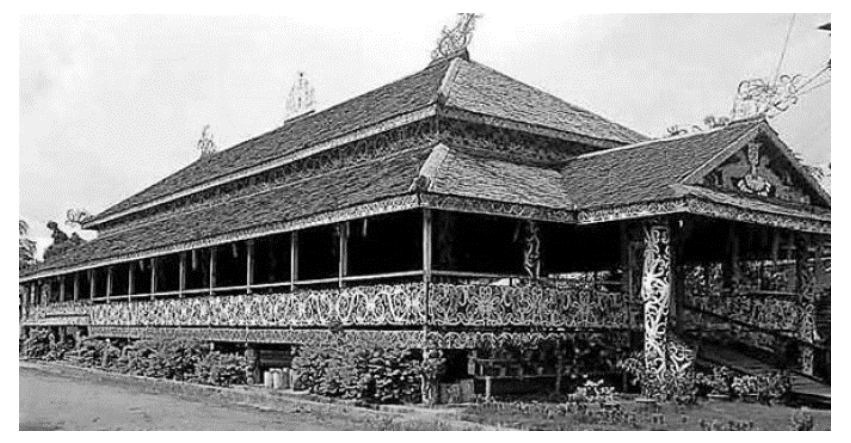

Gambar 2. Rumah Adat Lamin Kalimantan Timur

Sumber : https://architecture.verdant.id/rumah/adat/mengenal-bentuk-dan-ciri-khas-rumah-adat-lamin/

Pada saat ini Rumah Lamin lebih jarang dijumpai, karena termakan oleh zaman yang tergantikan dengan gaya rumah modern masa kini. Tetapi Rumah Lamin yang masih dijamin keasliannya dari zaman dahulu hingga masa kini masih terus eksis dan selalu menjadi perhatian bagi para pengunjung. Rumah Lamin sering kali dijadikan objek wisata mengenal kebudayaan Kalimantan Timur lebih dalam.

\section{Metode}

Kajian pada rancangan ini berdasarkan atas metode deskriptif analisis. Metode ini merupakan berupa paparan/ deskripsi yang terjadi saat ini terkait fenomena di sekitar lokasi tapak, disertai dengan literatur-literatur yang mendukung teori Arsitektur Neo-Vernakular Kalimantan Timur, yang terinspirasi dari rumah lamin sebagai rumah adat Kalimantan Timur. Analisa data bisa dilakukan secara kuantitatif. Penggunaan metode deskritif 
terdapat pada pembahasan mengenai teknik-teknik pengumpulan, pengolahan atau analisa dan penyajian ide perancangan. Langkah-langkah ini meliputi survey objek-objek komparasi, lokasi tapak untuk mendapatkan data-data dan komperasi yang berhubungan dengan objek rancangan.

\section{Hasil dan Diskusi}

\subsection{Konsep Rancangan}

Di bawah ini adalah diagram konsep yang diterapkan pada rancangan pusat industru kreatif ini, dengan menggunakan konsep makro "Reborn of Borneo" adalah mengembangkan budaya modern dengan menghidupkan kembali ciri khas dan tradisional asli Kalimantan Timur. Konsep bentuk "Attractive Culture" di terapkan dengan membuat bentukan penambahan dan pengurangan bentuk dasar pada massa bangunan, dan menciptakan unsur etnik dengan penambahan motif pada bidang.

Konsep mikro "Adaptive Culture" yaitu menciptakan ruang dengan menyesuaikan dari tiap fungsi dan kebutuhan dari kebudayaan suku asli Kalimantan Timur dengan menciptakan bukaan dan penghawaan yang sama dengan bangunan tradisionalnya diterapkan dengan desain yang baru menyesuaikan material dan bahan di zaman modern ini. Konsep Mikro "Terpusat" diterapkan pada penataan lahan yang mengarah pada satu titik tengah dimana titik tersebut merupakan lokasi bangunan utama yaitu gedung pengembangan pusat industri kreatif.

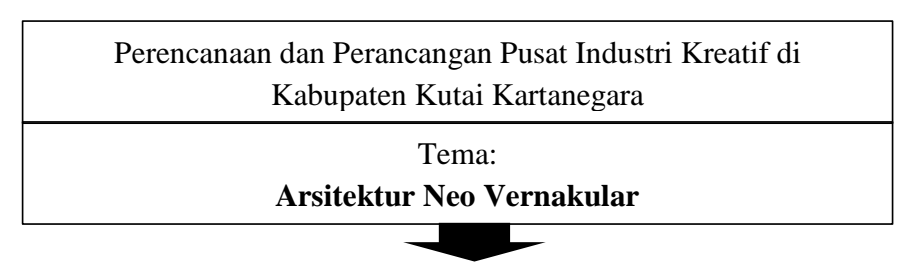

Arsitektur Neo Vernakular tidak hanya menerapkan elemen-elemen fisik yang diterapkan dalam bentuk modern tapi juga elemen non fisik seperti budaya, pola piker, kepercayaan, tata letak, religi dan lain-lain.

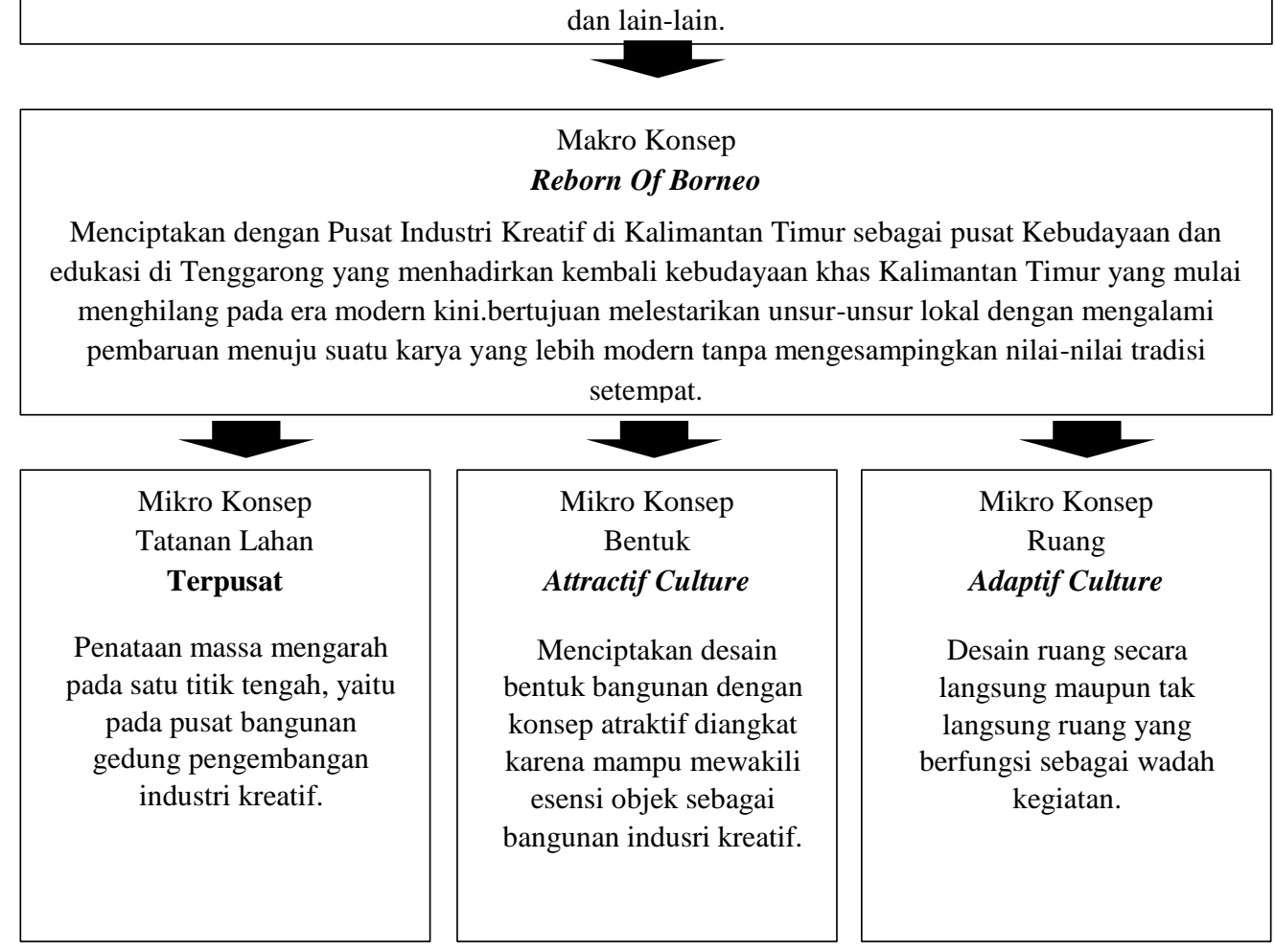

Gambar 3. Diagram Konsep Rancangan 


\subsection{Hasil Rancangan Desain Bentuk}

Gambar 4, 5, dan 6 berikut adalah tampilan bentuk bangunan Industri Kreatif dari tiap masing-masing kegunaan bangunan yang ada pada Pusat Industri Kreatif di Kabupaten Kutai Kartanegra, dari tampilan bentuk menyesuaikan dengan rumah adat khas Kalimantan Timur yaitu rumah panggung Lamin. Dengan dikombinasikan atap yang melalui transformasi sehingga terciptanya desain atap yang leih arsitektural. Dipadukan dengan motif-motif khas Kalimantan Timur seperti motif Kembang Jaong dan juga motif Tameng menambah esensi nilai etnik kebudayaan khas Kalimantan Timur.
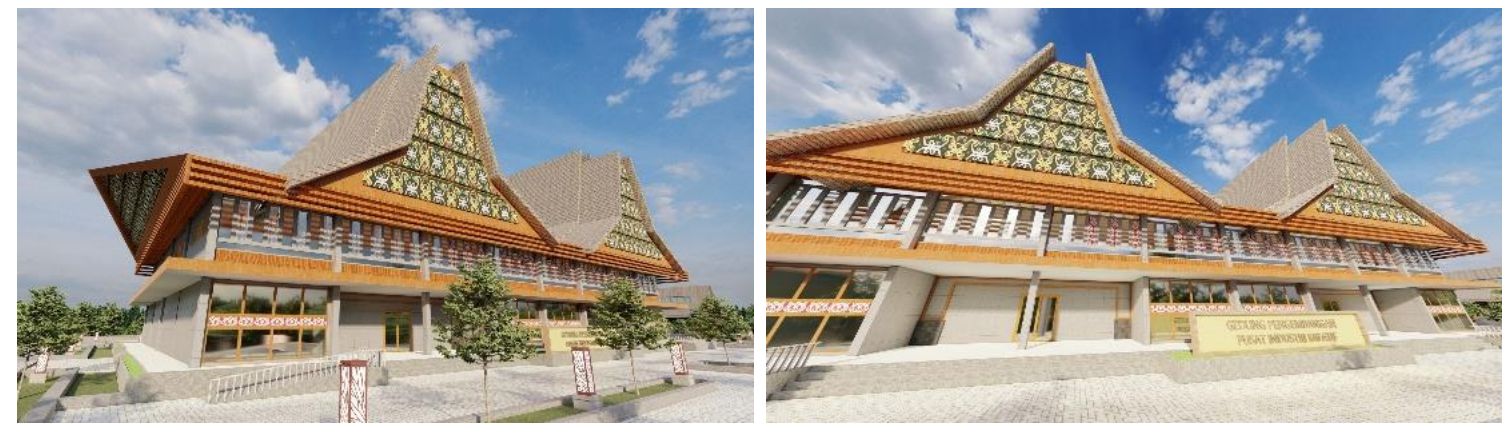

Gambar 4. Tampak Bangunan Pusat Pengembangan Industri Kreatif

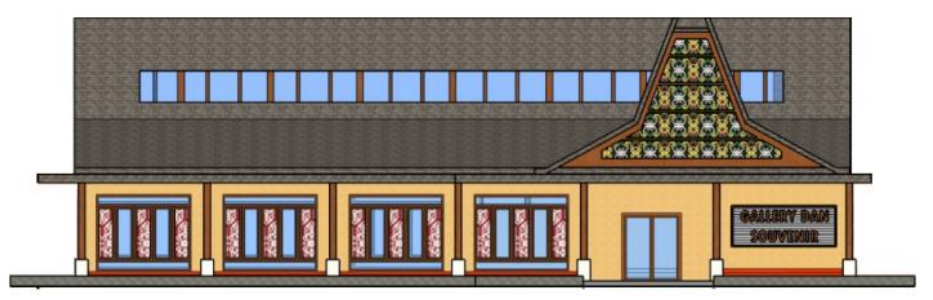

Gambar 5. Tampak Bangunan Gallery dan Souvenir
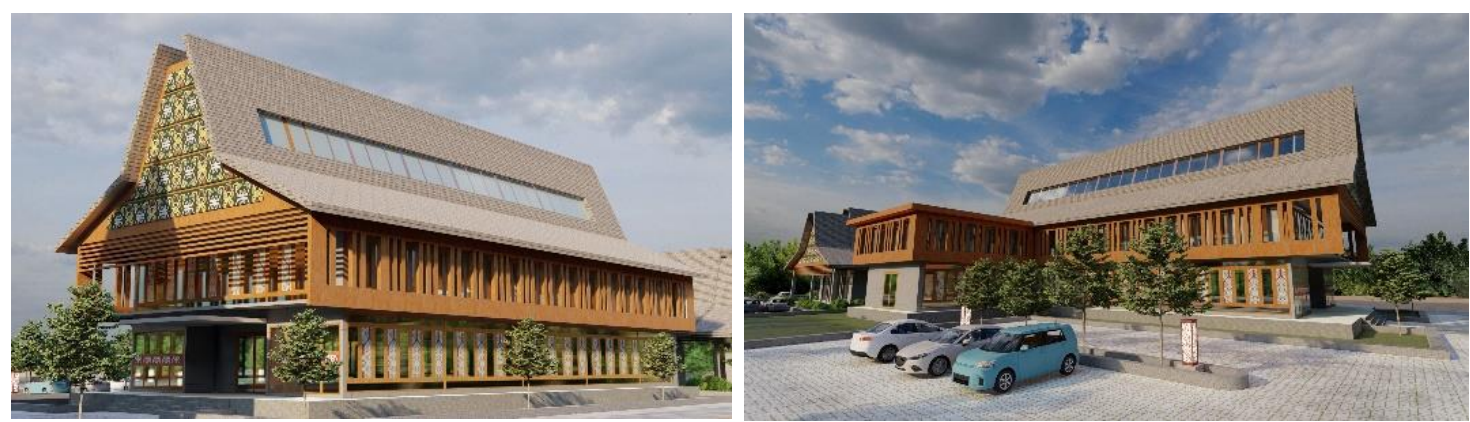

Gambar 6. Tampak Bangunan Exhibition

Dalam proses perancangannya, bangunan mengadopsi sebuah bentuk bangunan tradisional Kalimantan Timur, yaitu Rumah Lamin, dengan menerapkan material baru atau modern menjadi sebuah desain bangunan dengan fasad yang baru, menyesuaikan dengan tema konsep yaitu neo vernakular.

\section{Desain Ruang}

Pada Gambar 7 di bawah ini adalah salah satu desain dari ruang studio tari dimana ruang ini difungsikan sebagai tempat para penggerak seni tari berlatih secara indoor, visual kebudayaan yang dilakukan di dalam ruangan khusus. 


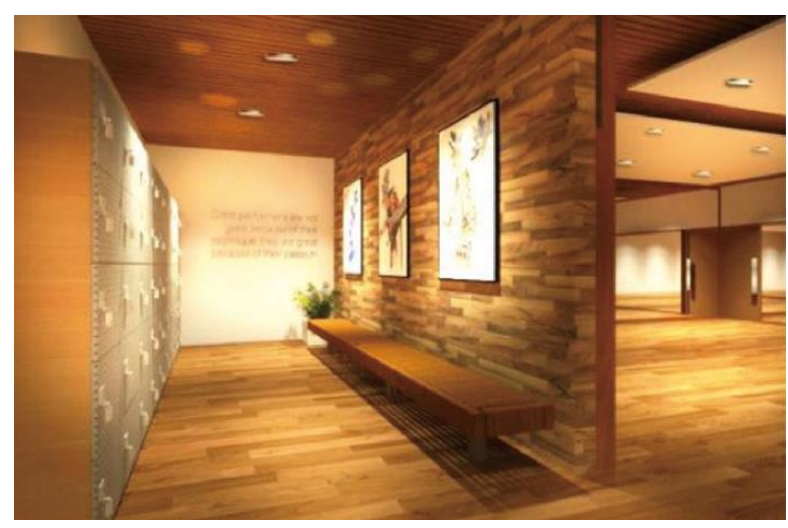

Gambar 7. Desaun Interior Studio Tari

Desain ruang pada ruang studio tari diberikan sentuhan khas Kalimantan dengan banyaknya penggunaan kayu dan motif kayu pada bagian dinding, plafon, dan juga lantai. Diketahui bahwa Kalimantan Timur merupakan salah satu penghasil kayu terbaik di dunia yang terkenal dengan kekokohan nya.

\section{Tatanan Lahan}

Konsep Terpusat adalah menciptakan sebuah tatanan lahan yang mampu mengomunikasikan kepada para pengunjung tentang berbagai fasilitas yang terdapat di dalamnya serta mengarahkan pengunjung ke berbagai fasilitas yang telah disediakan, baik yang berada di dalam lansekap maupun ke dalam bangunan dengan fasilitas yang dapat dikunjungi. Sehingga dari hal tersebut dapat memberikan kemudahan dan kenyamanan kepada pemakai atau pengguna rancangan ini.

Konsep mikro mengusung konsep terpusat yang berarti mengarahkan sebagian besar bangunan ke satu titik bagian tengah tepatnya pada bangunan utama yaitu gedung pengembangan industry kreatif. Terdapat beberapa area pada rancangan tapak yaitu, area pertunjukan indoor dan outdoor, area pengembangan industri kreatif, dan jua terdapat beberapa fasilitas pendukung diantaranya yaitu area terbuka hijau untuk pertunjukan outdoor, cafeteria, dan gallery souvenir.

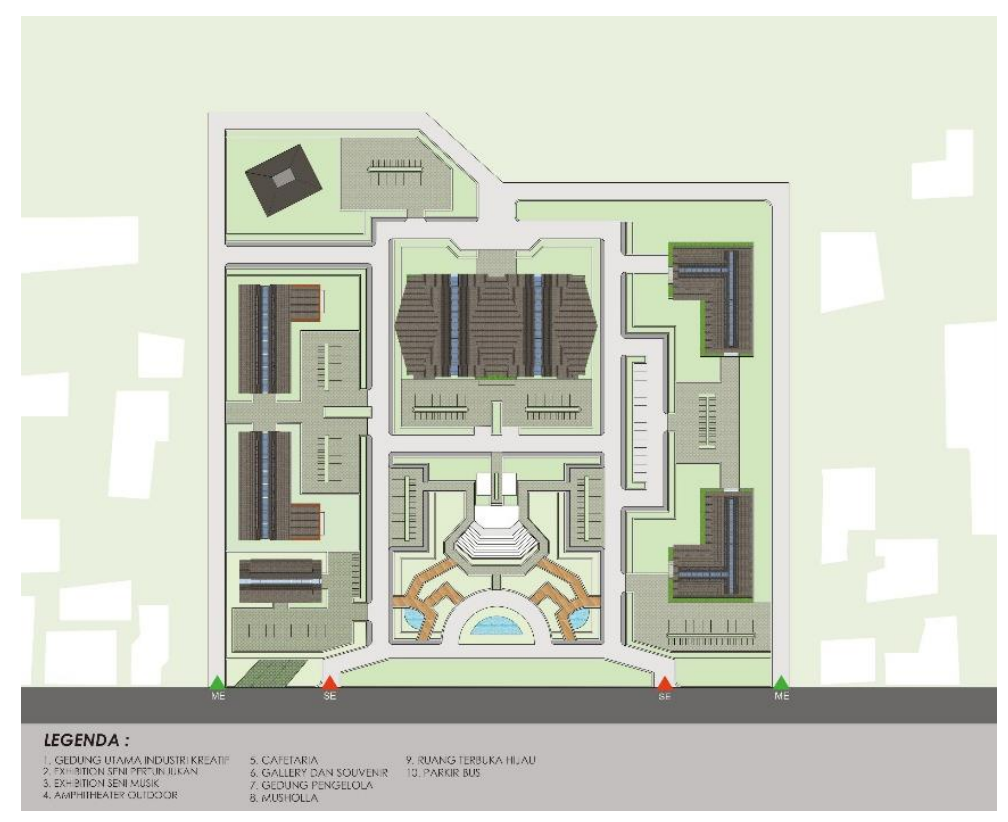

Gambar 8. Desain Tatanan Lahan 


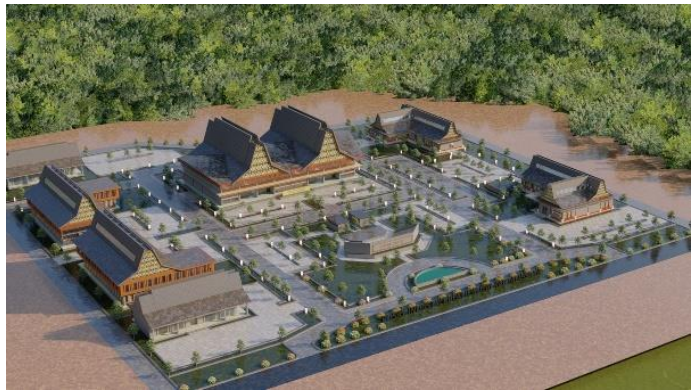

(a)

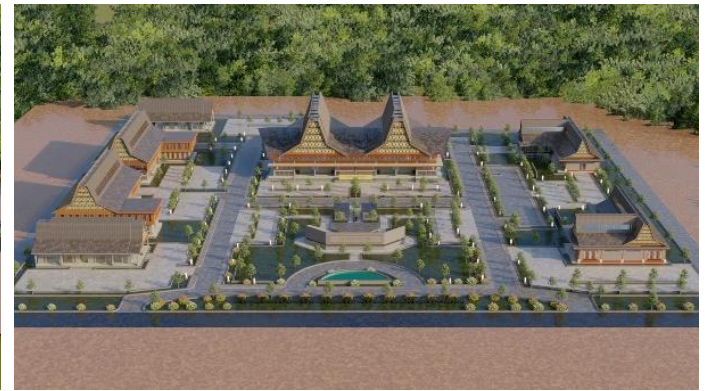

(b)

Gambar 9. (a dan b) Perspetif mata burung

Pada penataan Site Plan terlihat secara keseluruhan bentuk atap dari tiap-tiap bangunan dengan sangat jelas, Bentuk ruang terbuka hijau dan jalan akses utama menuju Pusat Industri Kreatif di Kalimantan Timur serta menuju ke bangunan lain-lainnya dengan memanfaatkan pencayahaan alami pada konsep terpusat berguna agar bangunan mendapatkan cayaha alami tanpa terhalangi oleh bangunan lainnya.

\section{Kesimpulan}

Penerapan konsep "develop culture" (mengembangkan kebudayaan) dengan pendekatan arsitektur Neo Vernakular pada Kompleks Taman Budaya Kalimantan Timur merupakan langkah untuk membangkitkan atau mengembangkan kebudayaan yang ada di Kalimantan Timur, dengan menerapkan tema arsitektur vernakular yang diharapkan menjadi obyek budaya edukasi yang dapat memberikan kontribusi positif bagi lingkungan alam dan sosial ekonomi masyarakat serta dapat menjadi obyek wisata bagi masyarakat.

\section{REFERENSI}

Astiti, N. K. A. (2015). Pengembangan Warisan Budaya di Tenggarong sebagai Daya Tarik Wisata Kalimantan Timur. Jurnal Destinasi Kepariwisataan Indonesia, $2(1)$. https://www.kemenparekraf.go.id/asset_admin/assets/uploads/media/old_all/JDP Vol_2 No_1 2015 Pengembangan Warisan Budaya di Tenggarong Sebagai Daya Tarik Wisata Kalimantan Timur.pdf

EIFAF Event Budaya Berlevel Internasional. (2016). Bagian Protokol Dan Komunikasi Pimpinan, Pemerintah Kabupaten Kutai Kertanegara. https://prokom.kukarkab.go.id/berita/sosial-budaya/eifaf-event-budayaberlevel-internasional

Karmelia, A. (2017). Penerapan Arsitektur Neo-Vernakular pada Stasiun Kiaracondong Bandung. Jurnal Repository Tugas Akhir Arsitektur, 3(1), 1-9. https://ars.itenas.ac.id/repository/index.php/repositoryta/article/viewFile/337/323

Kurniawan, I. (2015). Pembangunan Ekonomi Melalui Pariwisata pada Pesta Budaya Erau di Tenggarong, Kabupaten Kutai Kartanegara, Provinsi Kalimanan Timur. DEDIKASI (Jurnal Ilmiah Sosial, Hukum, Budaya), 32(1), 35-46. https://doi.org/https://doi.org/10.31293/ddk.v32i1.1412

Pengembangan Ekonomi Kreatif Indonesia 2025 (Rencana Pengembangan Ekonomi Kreatif Indonesia 2009 2015). (2008). Departemen Perdagangan Republik Indonesia. https://drive.google.com/file/d/1WOh9icnRNsHEj9xGWn5AluXBYjtssl3c/view

Purnamasari, M., Firzal, Y., \& Aldy, P. (2019). Pusat Wisata Kuliner di Siak dengan Pendekatan Arsitektur Neo Vernakular. Jurnal Online Mahasiswa (JOM) Bidang Teknik Dan Sains, 6(2). https://jom.unri.ac.id/index.php/JOMFTEKNIK/article/view/26303

Putra, D. P., Alhamdani, M. R., \& Gunawan, I. (2013). Pusat Industri Kreatif di Kota Pontianak. JMARS (Jurnal Mosaik Arsiektur),

https://doi.org/https://jurnal.untan.ac.id/index.php/jmarsitek/article/view/2108/2041

$1(1)$

Rumah Adat Lamin di Kalimantan Timur. (2020). PariwisataIndonesia.Id.

Rumah Lamin. (2021). In Rumah Belajar (Belajar untuk Semua). Kementerian Pendidikan dan Kebudayaan Republik Indonesia. https://petabudaya.belajar.kemdikbud.go.id/Repositorys/Lamin/

Sandroto, C. W., Ramawati, Y., \& Darmoyo, S. (2018). The Role of Competencies and Education in Increasing 
Entrepreneurial Intention in Creative Economy. International Research Journal of Business Studies, 11(1), 31-44. https://doi.org/https://doi.org/10.21632/irjbs

Semarakkan HUT Tenggarong ke-236, Festival Kota Raja dan Tenggarong Fair Kembali Digelar. (2018). Kutai Kartanegara.Com. https://www.kutaikartanegara.com/news.php?id=6385

Welianto, A. (2021). Rumah Lamin, Rumah Adat Kalimantan Timur. Kompas.Com. https://www.kompas.com/skola/read/2021/01/21/171500969/rumah-lamin-rumah-adat-kalimantan-timur 